\title{
Upgrading and expanding horizons of Journal of Ecology and Environment
}

\author{
Sangkyu Park
}

Dear readers and authors of Journal of Ecology and Environment:

As the new Editor-in-Chief, I would like to state my emphasis and visions in peer reviewing and editing our journal. Our editorial board members and I will commit to make Journal of Ecology and Environment a better journal. Our goal this year is to improve the overall quality of Journal of Ecology and Environment. To accomplish this goal, we will execute the following measures in running our journal.

First, we will invite high-quality review articles which provide condensed information on specific ecological issues. Currently, we have already invited review articles on various issues including plant reproduction ecology and freshwater eutrophication. In 2019, we hope to publish more review articles in our journal.

Second, we will reduce our peer review time to make our journal more attractive to submit. Already, we have changed our peer review system into "1 Editor-in-Chief and 8 Section Editors" system. Submitted manuscripts will be assigned to a Section Editor in one of four review sections (plant, animal, aquatic, and chemical/molecular) by the Editor-in-Chief. We believe that this new review system would be much efficient with quicker decision-making.

Third, we are actively promoting our published articles using media such as Flickr (www.flickr.com/photos/ 146571228@N05/), Blogger (howecoresearch.blogspot. com), and Facebook (www.facebook.com/journal.ecolen viron). Our Flickr site shares photos related to published articles in our journal while our Blogger site publishes postings about methodology issues in ecological research with examples published in our journal. Our Facebook page feeds news related to our journals including new Flickr and Blogger postings. Please contact me to promote your articles published in our journal.

Journal of Ecology and Environment is an open access and online journal, providing many merits in publishing your research articles. As it is an online journal, there are no limitations and no extra charges in publishing color graphs/photos and lengthy articles in our journal. Still, many authors are not fully aware of the potential and flexibility of our journal, submitting dull black and white graphs.

In 2019, we would like to cover wider areas in ecology by publishing articles in areas such as animal ecology, aquatic ecology, and chemical/molecular ecology. Also, we would like to see more submissions from more diverse regions all over the world such as Africa, Pacific, and America in addition to Eurasian continent. Our mission is to represent ecological research from under-represented regions through Journal of Ecology and Environment. So, please submit your precious research outcome. We will do our best to deliver your work to other researchers, policymakers, and citizens. We pursuit "open engagement" in ecology through Journal of Ecology and Environment, which is an open access and online journal.

By Sangkyu Park (Editor-in-Chief of Journal of Ecology and Environment)

Author's contributions

The author read and approved the final manuscript.

Competing interests

The authors declare that they have no competing interests.

\section{Publisher's Note}

Springer Nature remains neutral with regard to jurisdictional claims in published maps and institutional affiliations.

Received: 22 March 2019 Accepted: 22 March 2019 Published online: 02 April 2019 